\title{
Wat maakt een PGO-docent tot een goede docent?
}

\author{
H.J.M. van Berkel
}

\section{Samenvatting}

Vanwege de invoering van de Basiskwalificatie Onderwijs (BKO) staat onderwijs opnieuw in de belangstelling. Dat is terecht. De bij universitaire loopbanen gangbare eenzijdige nadruk op onderzoek heeft te lang geduurd. De noodzakelijke competenties voor een goed docent binnen de context van probleemgestuurd onderwijs (PGO) worden in deze opiniërende bijdrage geschetst. Een docent is een vakdidacticus die communiceert, coördineert en innoveert; deze vier dimensies voor een PGO-leeromgeving komen in dit artikel aan bod. (Berkel HJM van. Wat maakt een PGO-docent tot een goede docent? Tijdschrift voor Medisch Onderwijs 2009;28(4):167-174.)

\section{Inleiding}

De rectoren van de Nederlandse universiteiten hebben afgesproken de zogenoemde 'BKO- regelingen' van elkaar te erkennen. Deze Basiskwalificatie Onderwijs behelst een opleidingsprogramma waarin (aankomende) docenten didactisch worden geschoold. Immers, er is (nog steeds) geen wettelijke verplichting dat docenten die ingezet worden in de hoogste vorm van onderwijs welke mogelijk is - een wetenschappelijke opleiding - didactisch moeten zijn geschoold. Dat is merkwaardig. Docenten in het basisonderwijs moeten een didactische opleiding van vier jaar volgen, docenten in het voortgezet onderwijs een opleiding tussen een half en twee jaar, docenten in het HBO driehonderd uur en docenten op de universiteit nul uur. Er is daarom een negatieve correlatie tussen het niveau van het onderwijs en de eisen aan de didactische kwaliteiten van docenten. Dat geeft te denken.

Ook de NVMO, in het bijzonder de werkgroep Docentprofessionalisering, mengt zich actief in de discussie over competenties van docenten. Zo is er recent in Medical Teacher van Molenaar et al. een artikel verschenen over het competentieprofiel van een docent. ${ }^{1}$
Op de meeste universiteiten is het volgen van een didactische scholing, een BKOprogramma, verplicht. De erkenning van de BKO-regelingen houdt in dat wanneer docenten van universiteit A de overstap naar universiteit B willen maken, zij op universiteit $\mathrm{B}$ het programma niet meer hoeven te volgen. Dat zou dubbelop zijn. Ook al is het een kleine stap, het is een positieve ontwikkeling dat er eindelijk een formele kant komt aan de onderwijstaken van universitaire docenten. De volgende stap is uiteraard het geven van inhoud aan het scholingsprogramma. Je moet je gaan afvragen: 'Wat is eigenlijk een goede docent?' Dit opiniërende artikel wil aan deze discussie een steentje bijdragen. Gegeven het feit dat de meeste medische opleidingen de PGO-methodiek hanteren, beperkt deze bijdrage zich tot de docent die belast is met rollen in een PGO-organisatie.

\section{Wat maakt een PGO-docent tot een goede docent?}

Zoals uit deze bijdrage zal blijken gaan de docentrollen verder dan de rol van de tutor. Een PGO-organisatie wordt, sterker dan een meer klassieke benadering van onderwijs, gekarakteriseerd door multidisciplina- 
riteit, kleinschaligheid en (centrale) aansturing. De competenties die goede docenten zouden moeten bezitten, zullen daarop aan moeten sluiten.

Het is merkwaardig dat literatuur over karakteristieken van PGO-docenten schaars is. Er zijn veel artikelen over specifieke rollen, vooral de rol van tutor is regelmatig onderwerp van onderzoek. Echter, onderzoek naar wenselijke eigenschappen/competenties van docenten die functioneren in een PGO-leeromgeving c.q. leerorganisatie is zeldzaam. Wel zijn er veel opvattingen over docentcompetenties. Om te beginnen is daar de AMEE Guide No. 20: The good teacher is more than a lecturer - the twelve roles of the teacher (Harden en Crosby). ${ }^{2}$ Hoewel enigszins gedateerd, bevat de guide een bruikbare indeling van de verschillende rollen van docenten. De hoofddimensies van Harden en Crosby zijn: facilitator, functioneren als rolmodel, overdrager van informatie, ontwikkelaar, organisator en assessor. Vele daarna verschenen artikelen bouwen hierop voort. McLean et al. schetsen in een recent overzicht de wenselijke competenties van docenten in het medisch onderwijs. ${ }^{3}$ Zij doen dat in het licht van de trends in het medisch onderwijs. Tigelaar et al. ${ }^{4}$ verrichtten onderzoek naar docentcompetenties in het hoger onderwijs, zonder een specifiek accent te leggen op een PGO-leeromgeving. Wel is hun studie gericht op een docent in een student-centered leeromgeving. Maar dit omvat slechts een deel van een PGO-leeromgeving. Het is daarom niet verwonderlijk dat hun docentdimensies (de docent als mens, inhoudsdeskundige, onderwijsontwikkelaar, begeleider, evaluator, organisator en als levenslang lerende) slechts gedeeltelijk overeenkomen met de hier gehanteerde dimensies.

De decanen van de opleidingen Geneeskunde formeerde een task force met als opdracht te komen tot een weging van onderwijskundige kwalificaties van docenten in de geneeskunde. Er werd daartoe een framework ontwikkeld rond drie gebieden: doceeractiviteiten, organisatorische activiteiten en specifieke competenties. ${ }^{1}$ Vooral het eerste gebied, doceeractiviteiten, bevat een aantal deelgebieden die zeer herkenbaar zijn in iedere leeromgeving: ontwikkeling, organisatie, uitvoering, begeleiding, toetsing en evaluatie.

\section{Vier dimensies}

Een goede docent moet van vele markten thuis zijn. Iedereen zal erkennen dat een inspirerende collegever - ja, ook binnen PGO zijn colleges nuttig - goud waard is. We herinneren ons uit onze eigen opleiding nog steeds docenten die ons wisten te boeien met een interessant verhaal. Gelukkig zijn we de (vele) anderen vergeten die ons mateloos wisten te vervelen.

Maar hoe goed een docent ook een inspirerend verhaal kan houden, genoeg is het niet om een goede docent te zijn, zoals ook Harden en Crosby betogen. Het verhaal moet ook inhoud hebben; uitsluitend kunnen communiceren is onvoldoende. Dus docenten moeten ook deskundig zijn op een van de disciplines in de gezondheidswetenschappen. Docenten communiceren niet alleen met studenten over inhoud, maar zij zullen ook verantwoordelijk zijn voor een deel van de opleiding. Het dragen van verantwoordelijkheid impliceert dat zij dat gedeelte van het onderwijs ook moeten coördineren. Een goede docent moet dus ook een goede coördinator zijn. Maar goede coördinatoren zullen niet jaar in jaar uit hetzelfde deuntje ophoesten. Niet alleen omdat de inhoud van hun vakgebied verandert, maar ook omdat naar aanleiding van evaluaties en innovaties (denk aan ICTmogelijkheden) de presentatie van de inhoud mogelijkerwijs anders moet worden.

Zo zijn er vier dimensies van goede docenten te onderscheiden: vakdidactische deskundigheid, communicatieve vaardig- 
heden, coördinatievaardigheden en innovatiebereidheid. Hierna zal ieder van deze dimensies nader worden belicht en worden onderverdeeld.

\section{Vakdidactische deskundigheid}

Vakdidactische vaardigheden zijn vaardigheden die betrekking hebben op het omzetten van vakinhoud naar onderwijs. Docenten kunnen vooraanstaande geleerden zijn, maar wanneer zij er niet in slagen hun vakinhoudelijke kennis om te zetten in onderwijsmaterialen, in de breedste zin van het woord, zijn ze niet geschikt voor een baan aan een onderwijsinstelling. Onderwijsmaterialen als practicahandleidingen, beschrijvingen van problemen of casus, blokboeken, collegeplaatjes, studietoetsen, enzovoort, zijn betekenisloos zonder inhoud.

Docenten die deskundig zijn op het hele terrein van de opleiding waaraan ze een inhoudelijke bijdrage geven, zullen zeldzaam zijn. De meeste docenten zijn specialisten op een bepaald deelterrein van de opleiding. Daarom wordt een opleiding gegeven door vele deskundigen. Goede docenten realiseren zich dat. Toch is het professionals eigen hun vakgebied van een hogere orde te beschouwen dan dat van anderen. Deze docenten claimen bijvoorbeeld dat studieresultaten op 'hun' vak niet mogen worden gecompenseerd met die op andere vakken want 'het kan toch niet zo zijn dat studenten uiteindelijk slagen met een onvoldoende voor mijn vak'. Deze docenten claimen ook vaak een groter gedeelte van het curriculum. Dat maakt samenwerking met hen lastig. Die docenten realiseren zich onvoldoende dat ze 'slechts' een schakel zijn in een geheel.

Docenten zullen ook hun vak moeten bijhouden. Binnen het wetenschappelijk onderwijs is er niet voor niets een koppeling tussen onderwijs en onderzoek. Wetenschappelijk onderzoek zorgt voor voor- uitgang op een bepaald vakgebied. Zodra nieuwe ontwikkelingen breed zijn geaccepteerd door de vakgenoten, en dus de body of knowledge is uitgebreid, zal de ontwikkeling deel moeten gaan uitmaken van het curriculum. Hoe meer docenten bij onderzoek zijn betrokken, des te sneller ze op de hoogte zullen zijn van nieuwe ontwikkelingen. Hoewel het niet direct noodzakelijk is dat goede docenten tevens goede onderzoekers zijn, moeten goede docenten in ieder geval op de hoogte zijn van nieuwe ontwikkelingen. Zij moeten nieuwsgierig zijn naar nieuwe 'ontdekkingen' in hun vakgebied. Dat blijkt bijvoorbeeld uit de tijdschriften die zij lezen en uit lidmaatschappen van vakverenigingen. Misschien moeten zij wel een beetje vakidioot zijn. Vakidioten stralen vaak enthousiasme uit dat studenten weet te boeien.

Op de meeste vakgebieden, zeker op het gebied van geneeskunde, hebben ICT-ontwikkelingen hun intrede gedaan. ICT-ontwikkelingen omvatten meer dan het gebruik van een computer bij het registreren van patiëntgegevens. Medische onderzoeken vergen vrijwel altijd geavanceerde apparatuur. Mensen hebben vaak een welhaast natuurlijke huiver om met nieuwe dingen in zee te gaan. Toch is het ontegenzeggelijk waar dat nieuwe technologieën vrijwel ieder vakgebied enorm vooruit hebben geholpen. Maar ook directer in het onderwijs zijn ICT-ontwikkelingen. Denk bijvoorbeeld maar eens aan de elektronische leeromgevingen, zoals Blackboard, die veel opleidingen hanteren. Goede docenten mogen niet terughoudend zijn om zich verder te bekwamen in de mogelijkheden van computers in hun vakgebied en in het onderwijs.

\section{Communicatieve vaardigheden}

Communiceren is een veelomvattend begrip, ook voor docenten. De belangrijkste personen met wie docenten binnen het 
kader van de opleiding communiceren, zijn: collega-docenten, studenten, bestuurders en commissies, zoals de opleidingscommissie en de examencommissie. Ook het uitvoeren van onderwijsrollen is een vorm van communiceren, in het bijzonder de rol van collegegever.

Om met dit laatste te beginnen: college geven. Het geven van een hoorcollege heeft alles met communiceren te maken. De opdracht aan collegegevers is: koppel inhoud aan een boeiend verhaal. Het heeft iets van entertainen in zich. De rol van een college binnen de PGO-context is niet alleen het overbrengen van kennis. Het is immers bewezen dat personen weinig onthouden van iets wat hen mondeling is meegedeeld. Waar het ook om gaat, is studenten te interesseren voor een vakgebied. Dat kan op verschillende manieren. Goede collegegevers zijn op de hoogte van de voorkennis van hun gehoor en sluiten daarop aan. Goede collegegevers zijn ook in staat de context van hun boodschap te schetsen. En bovenal zijn goede collegegevers goede entertainers. Wanneer collegegevers iets anders doen dan het geijkte, bijvoorbeeld een film vertonen, aantrekkelijke plaatjes gebruiken en emoties weten te raken, dan wordt hun college beter onthouden. Uiteraard gaat het op de eerste plaats over de inhoud. Maar als de boodschap aantrekkelijk wordt verpakt, beklijft de inhoud beter. Niet iedere docent is een begiftigde spreker. Maar iedere universiteit verzorgt trainingen op het gebied van presentatietechnieken, omdat het geven van aantrekkelijke colleges is aan te leren.

Voor studenten is het belangrijk dat een docent benaderbaar is en antwoord geeft op hun vragen. Goede docenten laten in ieder geval de e-mails van studenten niet enkele weken onbeantwoord en zorgen er voor dat het studenten lukt hen te spreken, hetzij rechtstreeks ('mijn deur staat altijd open'), hetzij via een spreekuur. Onbereik- bare docenten geven studenten het gevoel dat de opleiding niet in hen is geïnteresseerd en dat kan negatieve gevolgen hebben voor de studievoortgang.

Goede docenten zijn ook docenten die binnen de opleiding spraakmakend zijn. Dat wil zeggen, alle betrokkenen bij de opleiding weten wie deze docenten zijn, waar ze voor staan en dat ze voor hun zaak opkomen. Met andere woorden, goede docenten zijn zichtbaar aanwezig in de opleiding. Een goede docent is zowel teamplayer als eigenzinnig. Teamplayereigenschappen zijn noodzakelijk omdat docenten deel uitmaken van een groep. Een docentencorps als geheel draagt de opleiding.

Maar goede docenten hebben ook een eigen mening die ze, uit professionele overwegingen, soms laten prevaleren boven het groepsbelang. Ze roepen soms 'boe' naar hun collega's. De boodschap is dan 'tot hier en niet verder'. Botsingen die daaruit voortkomen, zijn zeer herkenbaar in een organisatie die voor de meerderheid bestaat uit professionals. Een universiteit is een schoolvoorbeeld van een professionele organisatie. Docenten zijn immers in dienst genomen vanwege hun vakdeskundigheid. Dat mag een opleiding niet verloochenen. Voortdurend overleggen is een methode om conflicten die hieruit voortkomen, 'weg te masseren'. Het is daarom onterecht te menen dat op universiteiten teveel wordt vergaderd. $\mathrm{Nu}$ zal dat in een aantal best minder kunnen, maar doorgaans hebben vergaderingen de bedoeling om 'de neuzen in één richting te krijgen'. En dat kost nu eenmaal tijd. Van goede docenten mag worden verwacht dat ze voor hun vak opkomen, maar ook dat ze zich uiteindelijk weten te schikken in genomen besluiten. Ze moeten dus ook flexibel zijn.

Of docenten flexibel kunnen zijn, blijkt onder andere uit hun optreden in de opleidingscommissie en examencommissie. 
Dat zijn twee belangrijke commissies binnen iedere opleiding waar veel over onderwijs wordt gesproken en waar prioriteiten worden gelegd. Goede docenten zijn lid (geweest) van deze commissies en zullen zich in deze commissies inzetten voor het belang van de hele opleiding. Docenten die in dergelijke commissies te veel voor hun eigen vak opkomen zijn geen goede docenten daar deze commissies primair de kwaliteit van de opleiding als geheel behartigen. Eilandenrijkjes zijn contraproductief en belemmeren de consistentie van het curriculum.

\section{Coördinatievaardigheden}

Het coördineren van onderwijs waarvoor docenten verantwoordelijk zijn, is wellicht de meest in het oog lopende activiteit. De meeste docenten staan er ambivalent tegenover. Enerzijds vinden ze het een uitdaging om inhoudelijk goede studiematerialen te maken, anderzijds vergt het coördineren veel tijd die weinig met hun interesse heeft te maken. Zij moeten bijvoorbeeld anderen achter hun broek aan zitten om op tijd met toegezegde materialen te komen. Een coördinator werkt binnen de PGO-methodiek meestal in interdisciplinaire groepen omdat binnen een enkel blok of module de inbreng van verschillende disciplines wenselijk is.

Goede docenten kunnen samenwerken in een multidisciplinaire groep. Zij moeten de inbreng van anderen in het blok waarvoor ze verantwoordelijkheid dragen, weten te plaatsen, maar vooral weten te integreren. Een onderwijsblok is namelijk meer dan een optelsom van enkele disciplines. Overigens kom je zoiets nog vaak tegen binnen het PGO: een keurig multidisciplinair samengestelde groep die niet verder komt dan het aanleveren van monodisciplinaire taken. 'Doe jij dit dan doe ik dat, en zorg dat het voor een bepaalde datum af is', zo luidt dan de afspraak. Vervolgens worden de gemaakte taken/opdrachten achter elkaar gezet. Goede docenten echter doen moeite om taken/problemen te maken met de input van de verschillende disciplines in hun groep.

Als coördinator van een blok/module moet een docent het onderwijs waarvoor hij/zij verantwoordelijk is ook organiseren. Daar houden docenten in het algemeen niet van. Het liefst besteden ze dit uit, aan bureau Onderwijs bijvoorbeeld. Voor een groot gedeelte is dat meestal mogelijk, maar als het de coördinatie van de inhoud betreft, moeten docenten dat zelf doen: de groep bij elkaar roepen, taken verdelen, materialen verzamelen, bespreken en naar de drukker brengen, collegegevers benaderen, de toets op tijd af hebben, en hebben nagekeken, enzovoort. Het komt allemaal neer op organiseren. Goede docenten accepteren de noodzaak van dergelijke activiteiten als deel van hun taak en voeren ze nauwgezet uit. Uit blokevaluaties blijkt vaak dat er een hoge positieve correlatie is tussen de waardering voor een blok als geheel en de waardering voor de organisatie ervan.

Hoewel in formele zin de examencommissie hiervoor verantwoordelijkheid draagt, zijn het de coördinatoren van onderwijs die bepalen hoe hoog de lat komt te liggen voor studenten. Zij bepalen de moeilijkheid van de leerstof en de toetsvragen. Het is zaak om hierbij de realiteit niet uit het oog te verliezen. Docenten hebben in de meeste gevallen een groot aantal jaren beroepservaring. Zij vergeten nogal eens dat studenten twintigjarige jongens en meisjes zijn die net van het VWO komen. 'Oudere' professionals zijn beter in staat om allerlei verbanden te leggen tussen deeldisciplines. Het is verleidelijk dat ook van studenten te vragen. Vooral in toetsvragen willen docenten hun eigen kennis van het vak nog wel eens botvieren. Dat is onterecht. Studenten hebben gewoonweg nog niet het overzicht. Met 
andere woorden: soms leggen docenten de lat te hoog. Aan de andere kant is de opleiding academisch. De lat moet ook hoog liggen, het mag geen 'Zeer Uitgebreid Lager Onderwijs' worden, zoals Piet Vroon het universitaire onderwijs cynisch typeerde. Goede docenten leggen de lat hoog, maar zorgen er wel voor dat het haalbaar is. Bij het construeren van toetsvragen impliceert dit dat er naast feitenkennis (rijtjes en definities) ook vragen van een hoger cognitief niveau in de toets moeten worden opgenomen.

Op het moment dat blijkt dat er meer dan een gebruikelijk percentage studenten is gezakt, komt er een druk te liggen bij de verantwoordelijke docenten. Als dan uit een inhoudelijke en psychometrische analyse van de toets blijkt dat de toets geen feilen vertoont, zal de conclusie niet anders kunnen zijn dan dat studenten zich niet goed hebben voorbereid op de toets. Goede docenten zullen dan hun rug recht houden en geen concessies doen. Streng maar rechtvaardig is dan het motto. Als echter blijkt dat er wel degelijk iets mankeert aan de kwaliteit van de toets, zullen goede docenten initiatieven nemen om studenten daar niet de dupe van te laten worden.

Het is zo standaard geworden dat ieder blok/module aan een evaluatie wordt onderworpen. Via evaluaties spreken studenten hun waarderingen (positief of negatief) uit over aspecten van het gevolgde onderwijs. Daaruit zijn vervolgens conclusies te trekken die kunnen worden gebruikt bij het verbeteren van het onderwijs. Dat is ook het primaire doel van een evaluatie. Evalueren is het verzamelen van informatie ter verbetering van het onderwijs. Goede docenten zijn niet bang voor evaluatieresultaten. Integendeel, zij zien er naar uit. Niet alleen om de waarderingen te zien, maar ook om te bezien of het door hen zorgvuldig geconstrueerde onderwijs in overeenstemming met de verwachtingen heeft gefunctioneerd. Zij zijn als het ware eager-to-see de evaluatieresultaten.

\section{Innovatiebereidheid}

Als op basis van de evaluaties blijkt dat het onderwijs dient te worden veranderd, moeten docenten aan de slag. Zij zullen aanpassingen gaan doen. Dat is in veel gevallen een ingewikkeld proces. Studenten kunnen bijvoorbeeld klachten hebben over een bepaalde taak (onduidelijk, te open of gesloten, te moeilijk of gemakkelijk, enzovoort). Maar taken in een blok vormen tezamen een rode draad. Verandering aanbrengen in één taak heeft effect op andere taken. Goede docenten zijn daartoe in staat.

Goede docenten zullen echter ook van de gelegenheid gebruik maken om het onderwijs te innoveren. Bijvoorbeeld, binnen de kaders van de PGO-methodiek, het experimenteren met onderwijsvormen of toetsvormen. Studenten, vooral ouderejaars, vinden de strakke en uniforme regels van PGO nogal eens beknellend. Ook willen ze wel eens andere toetsvormen dan de bekende schriftelijke toetsen. Er is niets op tegen om daarvan af te wijken. Goede docenten durven dit soort experimentjes aan.

Innovaties doorvoeren is één ding, maar ze moeten ook op hun merites worden onderzocht. Met andere woorden, er moet een antwoord komen op de vraag of de verwachtingen zijn uitgekomen. Goede docenten zijn in staat zelf kleine experimentjes op het onderwijsgebied uit te voeren en te evalueren. Daarbij is het nodig dat ze onderwijskundige literatuur op toepassingsniveau beheersen.

\section{Tot slot}

Terug naar de BKO-regeling. In een landelijke werkgroep is consensus bereikt ten aanzien van de competenties waarover universitaire docenten binnen de onderstaande zes competentiegebieden moeten beschikken: 
- Professionele houding

- Ontwerpen van onderwijs

- Uitvoeren van onderwijs

- Begeleiden van studenten

- Organiseren en ontwikkelen van onderwijs

- Inhoudsdeskundigheid

Zij het in andere bewoordingen, deze gebieden komen terug in de dimensies die in dit artikel zijn besproken. Deze bijdrage beperkt zich echter tot de PGO-leeromgeving en geeft dus geen volledig beeld van de docentcompetenties in het algemeen. Daarover heeft Pedagogische Studiën recent een themanummer uitgebracht.

In Box 1 staan de in deze bijdrage vier beschreven dimensies van een goede PGOdocent onder elkaar plus de bijbehorende subdimensies. Het is beslist niet zo dat de (sub)dimensies onafhankelijk zijn van elkaar of geen overlap zullen hebben. De (sub)dimensies in de box vormen geen checklist in de zin van scoorbare aspecten. Dat zou erg naïef zijn. Daarvoor is het docentenberoep te holistisch; veel gedragingen van docenten zijn gerelateerd aan elkaar.

\section{Literatuur}

1. Molenaar WM, Zanting A, van Beukelen $P$, de Grave W, Baane JA, Bustraan JA, Engbers R, Fick ThE, Jacobs JCG, Vervoorn JM. A framework of teaching competencies across the medical education continuum. Med Teach 2009;31(4):390-96.

2. Harden RM, Crosby J. AMEE guide no. 20. The good teacher is more than a lecturer - the twelve roles of the teacher. Med Teach 2000;22: 334-347.

3. Mclean M, Cilliers F, van Wijk JM. Faculty development: yesterday, today and tomorrow. Med Teach 2008; 30:555-584.

4. Tigelaar EH, Dolmans DHJM, Wolfhagen HAP, Vleuten CPM van der. The development and validation of a framework for teaching competencies in higher education. Higher Education 2004; 48:253-268.
Juist in samenhang krijgen ze betekenis. Het overzicht biedt wel een kader waarmee PGO-docenten kunnen worden gekarakteriseerd.

Box 1. Dimensies voor het karakteriseren van docenten in een PGO-leeromgeving.

\section{Vakdidactische deskundigheid}

- Ziet in dat de eigen discipline een deel is van een groter geheel

- Houdt de vakliteratuur bij

- Is nieuwsgierig c.q. is vakidioot

- Koppelt ICT-ontwikkelingen aan het eigen vakgebied en onderwijs

Communicatieve vaardigheden

- Geeft inspirerende colleges

- Is benaderbaar voor studenten c.q. 'open deur'

- Is zichtbaar in de faculteit en is spraakmakend

- Werkt samen en is teamplayer

- Trekt grenzen en is eigenzinnig

- Is flexibel en heeft oog voor het geheel

Coördinatievaardigheden

- Werkt multidisciplinair samen

- Is een goed organisator

- Legt de lat haalbaar hoog

- Houdt de rug recht

- Is streng maar rechtvaardig

- Is nieuwsgierig naar evaluatieresultaten

Innovatiebereidheid

- Verricht kleine onderwijsexperimenten

- Probeert vernieuwingen binnen de PGO-context uit

- Houdt de didactische ontwikkelingen bij

De auteur:

Dr. H.J.M. van Berkel is universitair hoofddocent bij de Faculty of Health, Medicine \& Life Sciences aan de Universiteit Maastricht.

Correspondentieadres:

dr. H.J.M. van Berkel, Vakgroep O\&O, Postbus 616, 6200 MD Maastricht; e-mail: h.vanberkel@educ.unimaas.nl

Belangenconflict: geen gemeld

Financiële ondersteuning: geen gemeld 


\section{Summary}

The introduction of the basic educational qualification for academic teachers has put education in the spotlight. And rightly so. For too long academic careers have been exclusively determined by achievements in research. We will outline the competencies required of a good academic teacher in a problem-based curriculum. This teacher is an expert teacher in his/her field as well as a competent communicator, coordinator and innovator. These four dimensions will be discussed in relation to problem-based learning environments. (Berkel HJM van. What makes a PBL teacher a good teacher? Dutch Journal of Medical Education 2009;4(28):167-174.) 